\title{
Effects of operating conditions and pre-densification on the torrefaction products of sorghum straw
}

\author{
Xuanzuo Liu' ${ }^{1,2}$, Zonglu Yao ${ }^{1 *}$, Hongbin Cong ${ }^{3}$, Lixin Zhao ${ }^{1,3}$, Lili Huo ${ }^{1,3}$, Jinchun Song ${ }^{2}$ \\ (1. Institute of Environment and Sustainable Development in Agriculture, Chinese Academy of Agricultural Sciences, Beijing 100081, China; \\ 2. School of Mechanical Engineering and Automation, Northeastern University, Shenyang 110819, China; \\ 3. Key Laboratory of Energy Resource Utilization from Agriculture Residue of Ministry of Agriculture and Rural Affairs, \\ Academy of Agricultural Planning and Engineering, MARA, Beijing 100125, China)
}

\begin{abstract}
The effects of operating conditions and pre-densification on the torrefaction performance parameters and the properties of the torrefied sorghum straw were studied. A full-factor experiment was performed on a fixed tube furnace, in which sorghum straw powder and pellets were heated to $230^{\circ} \mathrm{C}, 260^{\circ} \mathrm{C}, 280^{\circ} \mathrm{C}$ and $300^{\circ} \mathrm{C}$ at $2.5^{\circ} \mathrm{C} / \mathrm{min}, 5^{\circ} \mathrm{C} / \mathrm{min}$ and $7.5^{\circ} \mathrm{C} / \mathrm{min}$, respectively. The pyrolysis characteristics of the sorghum straw torrefied under various operating conditions were complemented by thermogravimetric analysis. It was observed that the high temperature led to the high calorific value of the torrefied sorghum straw with an acceptable mass and energy yield. The sorghum straw torrefied at a temperature above $280^{\circ} \mathrm{C}$ had a higher heating value (HHV) that was comparable to that of the low rank coal while maintaining its energy yield above $85 \%$. The results suggested that temperature was an important factor determining the properties of the torrefied products, and the heating rate would affect the internal temperature of the torrefied biomass by affecting the heat transfer during the torrefaction. The energy densification index of the pellets decreased uniformly as the heating rate increased proportionally, indicating that pre-densification can be used as a potential method to solve the heat transfer delay in the fixed reactors at high heating rates, especially for high temperatures.
\end{abstract}

Keywords: torrefaction, pre-densification, pyrolysis characteristics, operating condition, sorghum straw, heat transfer DOI: $10.25165 /$ j.ijabe.20201304.5517

Citation: Liu X Z, Yao Z L, Cong H B, Zhao L X, Huo L L, Song J C. Effects of operating conditions and pre-densification on the torrefaction products of sorghum straw. Int J Agric \& Biol Eng, 2020; 13(4): 219-225.

\section{Introduction}

The urgent need to reduce $\mathrm{CO}_{2}, \mathrm{NO}_{\mathrm{x}}$ and $\mathrm{SO}_{\mathrm{x}}$ emissions promotes the development and utilization of renewable energy ${ }^{[1]}$. Wasted biomass is considered as a potential renewable energy source to replace fossil fuels for its trace amounts of sulfur, nitrogen and heavy metals and its widespread distribution ${ }^{[2]}$. Sorghum straw is one of the main sources of biomass energy because of the high drought tolerance, high energy storage and low production costs of sorghum ${ }^{[3]}$. However, the high moisture content, low energy density and low calorific value, etc. inherent properties of raw sorghum straw create challenges for transportation, storage and direct utilization efficiency ${ }^{[4]}$. Pyrolysis, heating biomass at high temperatures $\left(\sim 500^{\circ} \mathrm{C}\right)$ under

Received date: 2019-11-09 Accepted date: 2020-05-16

Biographies: Xuanzuo Liu, $\mathrm{PhD}$ candidate, research interests: biomass resource development and numerical simulation, Email:xuanzuo9001@163.com; Hongbin Cong, $\mathrm{PhD}$, research interests: biomass resource development, utilization and research, Email:conghongbin@163.com; Lixin Zhao, PhD, Professor, research interests: biomass resource development, utilization and research, Email: zhaolixin5092@163.com; Lili Huo, PhD, Researcher, research interest: biomass resource development, utilization and research, Email: huolili666@126.com; Jinchun Song, PhD, Professor, research interest: hydraulic drive and servo proportional control, mechatronics, Email: jchsong@mail.neu.edu.cn.

*Corresponding author: Zonglu Yao, $\mathrm{PhD}$, Researcher, research interest: biomass resource development, utilization and research. Institute of Environment and Sustainable Development in Agriculture, Chinese Academy of Agricultural Sciences, Beijing 100081, China. Tel: +86-13811216507, Email: yaozonglu@163.com. anaerobic conditions, is a commonly used thermochemical method for biomass upgrading. The factors affecting pyrolysis have been studied in many research, temperature and biomass type are the main factors affecting the distribution of pyrolysis products ${ }^{[5,6]}$. Chlorella heated at $350^{\circ} \mathrm{C}$ produced a maximum yield of bio-oil, while cottonseed yielded the maximum bio-oil yield at $550^{\circ} \mathrm{C}^{[7]}$.

Torrefaction, a thermal pretreatment method performed at $200^{\circ} \mathrm{C}-300^{\circ} \mathrm{C}$ under an inert atmosphere, which can convert raw biomass into materials with high energy density and low storage $\operatorname{cost}^{[8,9]}$. The destruction of the fibers in biomass during torrefaction can improve the grindability of biomass, reducing the grinding energy consumption ${ }^{[10,11]}$. The thermal decomposition of hemicellulose and cellulose and the destruction of the lignin structure in biomass during torrefaction make it easier to pyrolyze $^{[12]}$. Wen et al. ${ }^{[13]}$ found that hemicellulose in bamboo decreased considerably at $250^{\circ} \mathrm{C}-300^{\circ} \mathrm{C}$. Since the hydroxyl and $\mathrm{O}$-acetyl groups in hemicellulose are the main sources of water and acetic acid in bio-oil ${ }^{[14]}$, torrefaction has often been used prior to fast pyrolysis to decrease the moisture content and acidity in bio-oil ${ }^{[15]}$. In addition to the effect of torrefaction on pyrolysis or gasification, the reaction mechanism of torrefaction ${ }^{[16,17]}$ and the effect of temperature on torrefaction has also been studied in many research. Torrefaction can also be regarded as a low temperature pyrolysis of biomass, producing 'solid fuels' that can be used for heating and power production with satisfactory yields ${ }^{[18]}$.

Besides temperature, the heating rate and particle size of biomass also affect the torrefaction performance of the biomass because of heat transfer limitations. However, the effects of 
heating rate and pre-densification on torrefaction are rarely investigated. Although various devices have been designed to improve the heat transfer efficiency during biomass torrefaction, the relatively simple construction and behavior of the fixed reactor make it superior to other complicated reactors. This paper aims to investigate the effects of temperature, heating rate and densification on the heat transfer mechanism during torrefaction, which affects the torrefaction performance parameters and the properties of the torrefied biomass. In this work, the sorghum straw powder and the sorghum straw pellets were torrefied at different temperatures and heating rates in a fixed tube furnace. The thermal decomposition characteristics of sorghum straw torrefied under various operating conditions were complemented by thermogravimetric analysis. According to the experimental results, the effects of operating conditions and densification on torrefaction were analyzed.

\section{Materials and methods}

\subsection{Biomass characterization}

The sorghum straw pellets used in the torrefaction tests were purchased from Daxing District, Beijing, China. The pellets are cylinders with a diameter of about $6 \mathrm{~mm}$ and a length of about $12 \mathrm{~mm}$. The bulk density of the pellets is $803.1 \mathrm{~kg} / \mathrm{m}^{3}$. Since this study aims to investigate the effect of particle size on the heat transfer during torrefaction, the sorghum straw powder was obtained by grinding sorghum straw pellets and then passing through a 35 mesh sieve (particle size $<0.5 \mathrm{~mm}$ ). The density of the obtained sorghum straw powder is $175.6 \mathrm{~kg} / \mathrm{m}^{3}$.

The chemical composition of sorghum straw was measured by Van Soest method ${ }^{[19]}$, which was performed twice and the average of the two measurements was taken as the result. According to the measurement results, the sorghum straw used in this study was composed of $36.2 \%$ cellulose, $22.7 \%$ hemicellulose, and $33.3 \%$ lignin. The standard deviation of each measured value is less than 0.016 .

The ultimate analyses were performed using the PerkinElmer 2400CHNS/O elemental analyzer with a mass of approximately $1 \mathrm{mg} / \mathrm{sample}$. The ultimate analyses were performed twice for each sample and the presented percentages are the average of the obtained results, and the oxygen element $(\mathrm{O})$ was calculated from the difference between the elements $\mathrm{C}, \mathrm{H}, \mathrm{N}, \mathrm{S}$ and $100 \%$.

The moisture in the sample was measured by a drying oven, in which the uncovered glassware containing $(1 \pm 0.1) \mathrm{g}$ sample was heated at $105^{\circ} \mathrm{C} \pm 2^{\circ} \mathrm{C}$ for more than $180 \mathrm{~min}$. The mass reduction of the sample after heating was the moisture content in the sample. The volatile content was measured using a muffle furnace, in which a porcelain crucible containing $(1 \pm 0.1) \mathrm{g}$ sample was heated at $(900 \pm 10)^{\circ} \mathrm{C}$ for $(420 \pm 5) \mathrm{s}$. The mass reduction of the sample after heating was the volatile content in the sample. The ash content was measured by the muffle furnace, in which a porcelain crucible containing $(1 \pm 0.1) \mathrm{g}$ sample was heated from room temperature to $250^{\circ} \mathrm{C}$ at $5^{\circ} \mathrm{C} / \mathrm{min}$ and maintained for $60 \mathrm{~min}$, then raised to $550^{\circ} \mathrm{C}$ at $5^{\circ} \mathrm{C} / \mathrm{min}$ and maintained for more than $120 \mathrm{~min}$. The residual mass of the sample was the ash content in the sample. The fixed carbon content was determined by subtracting the moisture, volatile matter and ash content from $100 \%$. The proximate analyses were performed three times for each sample and the presented values are the media of the results.

The higher heating value (HHV) of the sample was measured using the TianHong ZDHW-A5 microcomputer automatic calorimeter. The measurements were performed three times for each sample and the average value was taken as the HHV of the tested sample. The lower heating value (LHV) of the sample was calculated by Equation $(1)^{[20]}$ :

$$
\mathrm{LHV}_{\text {dry }}=\mathrm{HHV}_{\text {dry }}-2.442 \times\left(8.936 \mathrm{H}_{\text {dry }} / 100\right)
$$

where, $\mathrm{H}_{\text {dry }}$ is the mass percentage of hydrogen element; LHV and $\mathrm{HHV}$ are given in MJ/kg. The properties of raw sorghum straw are shown in Table 1.

The thermal properties of the sample were measured using DECAGON thermal properties analyzer KD2 Pro. The presented values are the media of measurements taken at three different locations of the sample, as shown in Table 2.

The standard deviations of the three measurements of ultimate analysis, proximate analysis, calorific value and thermal properties of raw sorghum straw are no more than $0.0039,0.0022,0.17$ and 0.015 .

Table 1 Raw sorghum straw properties

\begin{tabular}{|c|c|c|c|c|c|}
\hline \multicolumn{2}{|c|}{$\begin{array}{l}\text { Ultimate analysis } \\
\qquad / \mathrm{wt} \%, \mathrm{db}\end{array}$} & \multicolumn{2}{|c|}{$\begin{array}{l}\text { Proximate analysis } \\
\text { /wt. } \%, \mathrm{db}\end{array}$} & \multicolumn{2}{|c|}{$\begin{array}{l}\text { Calorific value } \\
/ \mathrm{MJ} \cdot \mathrm{kg}^{-1}, \mathrm{db}\end{array}$} \\
\hline $\mathrm{C}$ & $49.36 \pm 0.50$ & Moisture & $1.02 \pm 0.00$ & HHV & $19.86 \pm 0.22$ \\
\hline $\mathrm{H}$ & $5.76 \pm 0.08$ & Volatile Matter & $85.22 \pm 0.25$ & LHV & $18.58 \pm 0.24$ \\
\hline $\mathrm{N}$ & $0.23 \pm 0.02$ & Fixed Carbon & $12.81 \pm 0.27$ & & \\
\hline O* & $44.45 \pm 0.42$ & Ash & $0.95 \pm 0.02$ & & \\
\hline
\end{tabular}

Note: db means dry basis; * means by difference.

Table 2 Thermal properties of sorghum straw with different particle sizes

\begin{tabular}{|c|c|c|c|c|c|}
\hline \multicolumn{2}{|c|}{$\begin{array}{l}\text { Thermal conductivity } \\
\qquad / \mathrm{W} \cdot \mathrm{m}^{-1} \cdot \mathrm{K}^{-1}\end{array}$} & \multicolumn{2}{|c|}{$\begin{array}{l}\text { Volumetric specific } \\
\text { heat } / \mathrm{MJ} \cdot \mathrm{m}^{-3} \cdot \mathrm{K}^{-1}\end{array}$} & \multicolumn{2}{|c|}{$\begin{array}{l}\text { Thermal diffusivity } \\
\qquad / \mathrm{mm}^{2} \cdot \mathrm{s}^{-1}\end{array}$} \\
\hline Powder & $0.09 \pm 0.01$ & Powder & $0.69 \pm 0.01$ & Powder & $0.14 \pm 0.01$ \\
\hline Pellets & $0.21 \pm 0.02$ & Pellets & $1.85 \pm 0.01$ & Pellets & $0.10 \pm 0.02$ \\
\hline
\end{tabular}

\subsection{Torrefaction experiments}

The torrefaction tests were carried out in OTF-1200X-100 fixed tube furnace. Approximately $50 \mathrm{~g}$ sample was evenly dispersed in a quartz boat with a diameter of $80 \mathrm{~mm}$ and a length of $200 \mathrm{~mm}$, and the quartz boat was placed in the middle of the furnace tube with a diameter of $94 \mathrm{~mm}$ and a length of $1000 \mathrm{~mm}$. Two cylindrical carbon blocks with a diameter of $92 \mathrm{~mm}$ and a height of $50 \mathrm{~mm}$ were inserted into the two ends of the furnace tube to reduce the heat dissipation at both ends of the tube. Nitrogen was used as the inert gas, and a wet flow meter was connected between the nitrogen cylinder and the tube furnace to measure the nitrogen amount.

Before heating the sample, approximately $20 \mathrm{~L}$ nitrogen was introduced into the tube to drain the air in the tube. When the sample was heated, the nitrogen flow rate was reduced to $150 \mathrm{~mL} / \mathrm{min}$ to reduce the heat loss caused by the nitrogen flow. The sample was first heated to $105^{\circ} \mathrm{C}$ and held for $5 \mathrm{~min}$, and then heated to a specified torrefaction temperature $\left(\mathrm{T}_{\text {tor }}\right)$ at a specified heating rate and held for $10 \mathrm{~min}$ at the set temperature. When tube temperature dropped to $100^{\circ} \mathrm{C}$, the quartz boat containing the torrefied sample was taken out of the tube. A full factorial experimental design was adopted to investigate the effects of temperature, heating rate and densification on torrefaction. The specified test values for temperature and heating rate are listed in Table 3.

Three torrefaction performance parameters, mass yield $\left(M_{\mathrm{Y}}\right)$, energy densification index $\left(I_{\mathrm{ED}}\right)$ and energy yield $\left(E_{\mathrm{Y}}\right)$ are defined 
as follows ${ }^{[21]}$ :

$$
\begin{gathered}
M_{\mathrm{Y}}\left(\%, \mathrm{~d} \text { a) }\left.\notin \frac{m_{\mathrm{t} \text { o r r e f i e d }}}{m_{\mathrm{s} \text { o r g h u }}}\right|_{\mathrm{d} \mathrm{a}}\right. \text { o } \\
\left.I_{\mathrm{ED}}(-)\right|_{\mathrm{daf}}=\left.\frac{\operatorname{LHV}_{\text {torrefied sorghum }}}{\mathrm{LHV}_{\text {sorghum }}}\right|_{\text {daf }} \\
E_{\mathrm{Y}}(\%, \text { daf })=\left.M_{\mathrm{Y}}(\%, \text { daf }) * I_{\mathrm{ED}}(-)\right|_{\text {daf }}
\end{gathered}
$$

\subsection{Thermogravimetric analysis (TGA)}

Thermogravimetric (TG) tests were performed in a SHIMADZU simultaneous TGA/DTA analyzer model DTG-60A. The TG curves were calibrated before the TG tests according to the instrument instructions. The sample used in the TG test was approximately $7 \mathrm{mg}$, and nitrogen (99.99\% purity) with a flow rate of $100 \mathrm{~mL} / \mathrm{min}$ was used as the purge gas. The samples were heated from room temperature to $900^{\circ} \mathrm{C}$ at $5^{\circ} \mathrm{C} / \mathrm{min}, 10^{\circ} \mathrm{C} / \mathrm{min}$, $15^{\circ} \mathrm{C} / \mathrm{min}$ and $20^{\circ} \mathrm{C} / \mathrm{min}$, respectively, and the TG curves were recorded by the analyzer software.

\section{Results and discussion}

\subsection{Effects of operating conditions on torrefaction}

Table 3 presents torrefaction performance parameters and calorific values of the torrefied sorghum straw, the standard deviations of the performance parameters and the calorific values are less than 0.098 and 1.093. The mass yield $\left(M_{\mathrm{Y}}\right)$ and energy yield $\left(E_{\mathrm{Y}}\right)$ of torrefied sorghum straw decreased as the temperature increased, which mainly results from the thermal decomposition of hemicellulose for its low degree of polymerization ${ }^{[22]}$.

The main chemical properties of torrefied sorghum straw are listed in Table 4, and the standard deviations of experimental values are less than 0.037. The increased temperature led to a deepened thermal degradation of sorghum straw, which can be deduced from the following results: (a) The color of torrefied sorghum straw changed from faint yellow to brownish black or even dark with the increased temperature, as shown in Figure 1, the volatile content decreased while the ash and fixed carbon content increased as the temperature increased, especially for temperatures above $260^{\circ} \mathrm{C}$. (c) The hydrogen and oxygen content of sorghum straw decreased while carbon content increased as the temperature increased. These were consistent with the results observed by Brachi et al. ${ }^{[23]}$, who found that the presence of $\mathrm{CO}_{2}$ and $\mathrm{H}_{2} \mathrm{O}$ in the volatiles when biomass was heated from $225^{\circ} \mathrm{C}$ to $300^{\circ} \mathrm{C}$. The mass loss of the torrefied sorghum straw is mainly due to the decarboxylation and dehydration of hemicellulose, which releases $\mathrm{CO}_{2}$ and $\mathrm{H}_{2} \mathrm{O}$ that richer in oxygen and hydrogen than carbon ${ }^{[24]}$. However, the nitrogen content of the torrefied sorghum straw showed an

\begin{tabular}{|c|c|c|c|c|c|c|c|}
\hline \multirow{2}{*}{$\begin{array}{l}\text { Test } \\
\text { No. }\end{array}$} & \multirow{2}{*}{$\begin{array}{c}\mathrm{HR} \\
/^{\circ} \mathrm{C} \cdot \min ^{-1}\end{array}$} & \multirow{2}{*}{$\begin{array}{l}\mathrm{T}_{\text {tor }} \\
/{ }^{\circ} \mathrm{C}\end{array}$} & \multicolumn{3}{|c|}{ Torrefaction performance parameters } & \multicolumn{2}{|c|}{ Calorific value $/ \mathrm{MJ} \cdot \mathrm{kg}^{-1}, \mathrm{db}$} \\
\hline & & & $M_{\mathrm{Y}} / \%$,daf & $I_{\mathrm{ED}}(-)$ & $E_{\mathrm{Y}} / \%$, daf & HHV & LHV \\
\hline 1 & 2.5 & 230 & $91.56 \pm 0.38$ & $1.07 \pm 0.00$ & $97.97 \pm 0.16$ & $20.67 \pm 0.69$ & $19.49 \pm 0.66$ \\
\hline 2 & 2.5 & 260 & $85.44 \pm 0.47$ & $1.10 \pm 0.01$ & $93.98 \pm 0.38$ & $21.47 \pm 0.74$ & $20.34 \pm 0.77$ \\
\hline 3 & 2.5 & 280 & $73.73 \pm 1.13$ & $1.18 \pm 0.01$ & $87.02 \pm 0.27$ & $23.19 \pm 0.87$ & $22.12 \pm 0.92$ \\
\hline 4 & 2.5 & 300 & $60.02 \pm 0.81$ & $1.29 \pm 0.04$ & $77.43 \pm 1.14$ & $26.17 \pm 1.00$ & $25.14 \pm 0.98$ \\
\hline 5 & 5 & 230 & $95.46 \pm 0.26$ & $1.04 \pm 0.01$ & $99.28 \pm 0.67$ & $20.36 \pm 1.01$ & $19.13 \pm 1.05$ \\
\hline 6 & 5 & 260 & $90.63 \pm 0.71$ & $1.08 \pm 0.02$ & $97.87 \pm 1.22$ & $20.94 \pm 1.27$ & $19.81 \pm 1.23$ \\
\hline 7 & 5 & 280 & $82.48 \pm 2.00$ & $1.11 \pm 0.07$ & $91.55 \pm 3.62$ & $22.23 \pm 1.23$ & $21.12 \pm 1.23$ \\
\hline 8 & 5 & 300 & $71.22 \pm 2.35$ & $1.20 \pm 0.12$ & $85.45 \pm 5.85$ & $25.01 \pm 1.35$ & $23.95 \pm 1.40$ \\
\hline 9 & 7.5 & 230 & $96.96 \pm 1.08$ & $1.03 \pm 0.01$ & $99.87 \pm 0.89$ & $20.10 \pm 0.56$ & $18.86 \pm 0.66$ \\
\hline 10 & 7.5 & 260 & $92.62 \pm 1.03$ & $1.07 \pm 0.01$ & $99.10 \pm 0.51$ & $20.70 \pm 0.85$ & $19.47 \pm 0.92$ \\
\hline 12 & 7.5 & 300 & $76.97 \pm 1.97$ & $1.15 \pm 0.05$ & $88.52 \pm 1.71$ & $22.70 \pm 1.67$ & $21.62 \pm 1.68$ \\
\hline
\end{tabular}
irregular change with the increased temperature.

Table 3 Torrefaction conditions and results of sorghum straw powder

\begin{tabular}{|c|c|c|c|c|c|c|c|}
\hline \multirow{2}{*}{$\begin{array}{l}\text { Test } \\
\text { No. }\end{array}$} & \multicolumn{4}{|c|}{ Ultimate analysis/wt.\%, db } & \multicolumn{3}{|c|}{ Proximate analysis/wt. $\%, \mathrm{db}$} \\
\hline & $\mathrm{C}$ & $\mathrm{H}$ & $\mathrm{N}$ & $\mathrm{O}^{*}$ & Volatile & Ash & $\mathrm{FC}$ \\
\hline 1 & $51.86 \pm 0.58$ & $5.41 \pm 0.12$ & $0.43 \pm 0.03$ & $42.07 \pm 0.45$ & $82.73 \pm 0.98$ & $1.09 \pm 0.02$ & $15.17 \pm 0.96$ \\
\hline 2 & $54.35 \pm 0.82$ & $5.18 \pm 0.15$ & $0.43 \pm 0.04$ & $39.78 \pm 0.69$ & $79.88 \pm 0.91$ & $1.23 \pm 0.03$ & $17.88 \pm 0.88$ \\
\hline 3 & $60.01 \pm 1.09$ & $4.92 \pm 0.23$ & $0.43 \pm 0.02$ & $34.30 \pm 0.81$ & $70.84 \pm 1.12$ & $1.70 \pm 0.10$ & $26.44 \pm 1.02$ \\
\hline 4 & $63.62 \pm 5.21$ & $4.72 \pm 0.45$ & $0.27 \pm 0.04$ & $31.22 \pm 4.83$ & $60.91 \pm 1.77$ & $1.98 \pm 0.13$ & $36.09 \pm 1.65$ \\
\hline 5 & $50.74 \pm 0.78$ & $5.60 \pm 0.37$ & $0.36 \pm 0.04$ & $43.21 \pm 0.56$ & $83.90 \pm 1.82$ & $1.10 \pm 0.09$ & $13.99 \pm 1.80$ \\
\hline 6 & $53.09 \pm 0.94$ & $5.32 \pm 0.32$ & $0.28 \pm 0.03$ & $41.12 \pm 1.12$ & $81.25 \pm 1.48$ & $1.21 \pm 0.05$ & $16.52 \pm 1.42$ \\
\hline 7 & $54.80 \pm 1.24$ & $5.09 \pm 0.23$ & $0.23 \pm 0.03$ & $39.68 \pm 1.18$ & $75.03 \pm 1.25$ & $1.46 \pm 0.10$ & $22.49 \pm 1.17$ \\
\hline 8 & $60.01 \pm 1.65$ & $4.85 \pm 0.24$ & $0.21 \pm 0.02$ & $34.75 \pm 1.46$ & $65.87 \pm 3.05$ & $1.89 \pm 0.17$ & $31.22 \pm 2.89$ \\
\hline 9 & $50.49 \pm 0.97$ & $5.65 \pm 0.44$ & $0.25 \pm 0.02$ & $43.42 \pm 0.45$ & $84.01 \pm 1.36$ & $1.13 \pm 0.02$ & $13.85 \pm 1.36$ \\
\hline 10 & $51.87 \pm 0.85$ & $5.63 \pm 0.53$ & $0.25 \pm 0.03$ & $42.05 \pm 0.56$ & $82.64 \pm 1.29$ & $1.19 \pm 0.05$ & $15.16 \pm 1.26$ \\
\hline 11 & $53.23 \pm 0.85$ & $5.22 \pm 0.21$ & $0.22 \pm 0.03$ & $41.12 \pm 0.97$ & $77.55 \pm 1.46$ & $1.35 \pm 0.06$ & $20.09 \pm 1.41$ \\
\hline 12 & $55.97 \pm 2.40$ & $4.94 \pm 0.11$ & $0.31 \pm 0.04$ & $38.59 \pm 2.37$ & $73.42 \pm 3.00$ & $1.59 \pm 0.11$ & $23.97 \pm 2.93$ \\
\hline
\end{tabular}

Note: daf means dry-ash-free; db means dry basis; HR means heating rate.

Table 4 Main chemical properties of torrefied sorghum straw powder

Note: db, dry basis; * means by difference. 


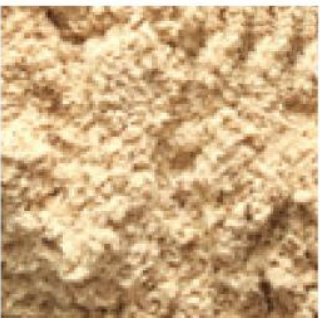

a. $30^{\circ} \mathrm{C}$

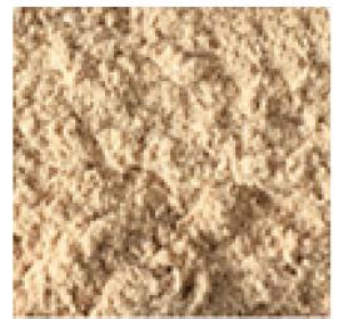

b. $230^{\circ} \mathrm{C}$

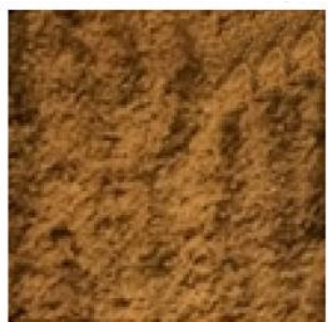

c. $260^{\circ} \mathrm{C}$

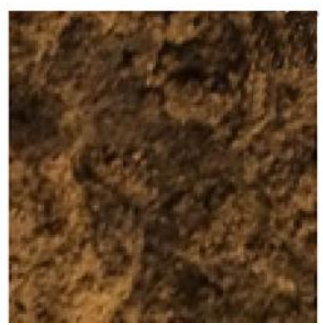

d. $280^{\circ} \mathrm{C}$

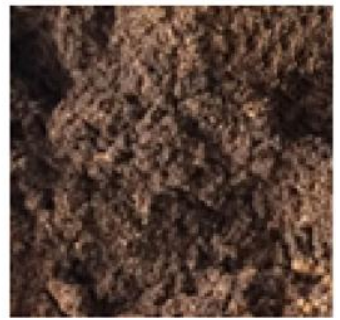

e. $300^{\circ} \mathrm{C}$

Figure 1 Snapshots of sorghum straw powder torrefied at $2.5^{\circ} \mathrm{C} / \mathrm{min}$

The decrease in the hydrogen-to-carbon $(\mathrm{H} / \mathrm{C})$ and oxygen-to-carbon $(\mathrm{O} / \mathrm{C})$ elemental ratio of the torrefied sorghum straw resulted in an increase in higher heating value (HHV) of the torrefied sorghum straw, as shown in Table 3 and Figure 2. As the temperature increased, the composition of the torrefied sorghum straw moved from the characteristic region of biomass to that of low-rank fossil fuels such as peat and brown coal. The torrefied sorghum straw, whose energy content increased by a factor above 1.1, provided an HHV on a dry basis comparable to that of low rank coal ${ }^{[25]}$. These results are in line with the typical mass and energy yields obtained from the previous biomass torrefaction studies $^{[26]}$.

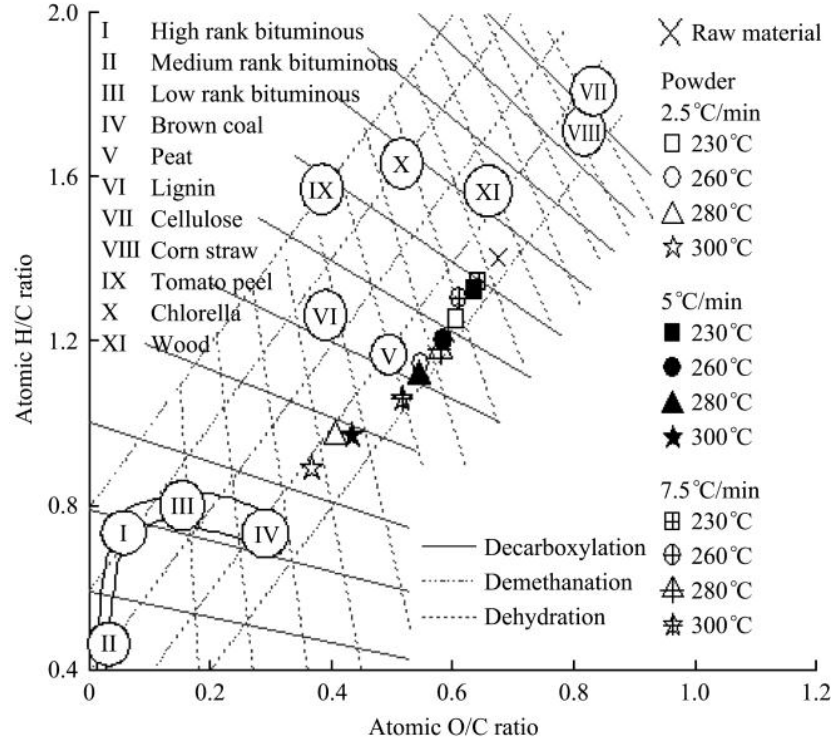

Figure 2 Van Krevelen diagram for torrefied sorghum straw powder

Affected by heat transfer limitations, the mass loss of torrefied sorghum straw decreased with the increased heating rate at the same temperature. The changes in the content of carbon, hydrogen and oxygen decreased as the heating rate increased, indicating that the thermal degradation degree of sorghum straw decreased as the heating rate increased. In detail, the yields and properties of the sorghum straw torrefied at $260^{\circ} \mathrm{C}$ and $2.5^{\circ} \mathrm{C} / \mathrm{min}$ are comparable to those torrefied at $280^{\circ} \mathrm{C}$ and $7.5^{\circ} \mathrm{C} / \mathrm{min}$. The calorific values of the sorghum straw treated at $300^{\circ} \mathrm{C}$ and $7.5^{\circ} \mathrm{C} / \mathrm{min}$ were lower than those of the sorghum straw treated at $280^{\circ} \mathrm{C}$ and $2.5^{\circ} \mathrm{C} / \mathrm{min}$. The higher the temperature was, the greater the effect of heating rate on torrefaction. This is because the high heating rate increases the thermal resistance inside the sorghum straw, which delays the heat transferred from the heat wall to the inside of the sorghum straw and lowers the temperature of the sorghum straw torrefied in the quartz boat. The high heating rate causes thermal heterogeneity of sorghum straw heated in the quartz boat. In addition, the consolidation of the sorghum straw powder torrefied in the fixed tube furnace also results in uneven temperature distribution.

\subsection{Effects of pre-densification on torrefaction}

Tables 5 and 6 list the main results of the sorghum straw pellets torrefaction tests, the standard deviations of the torrefaction performance parameters, main chemical properties and calorific values are less than $0.043,0.015$ and 1.108 . The mass yield $\left(M_{\mathrm{Y}}\right)$ of the sorghum straw pellets torrefied at a temperature above $230^{\circ} \mathrm{C}$ was lower than that of the sorghum straw powder torrefied under the same operating conditions, and the energy densification index $\left(I_{\mathrm{ED}}\right)$ of the torrefied sorghum straw pellets was higher than that of the torrefied sorghum straw powder. Compared with the torrefied sorghum straw powder, under the same operating conditions, the sorghum straw pellets torrefied at temperatures above $230^{\circ} \mathrm{C}$ have higher carbon content and lower oxygen content, which indicates that the sorghum straw pellets yielded a higher thermal degradation degree when the temperature was above $230^{\circ} \mathrm{C}$.

Table 5 Torrefaction conditions and results of sorghum straw pellets

\begin{tabular}{|c|c|c|c|c|c|c|c|}
\hline \multirow{2}{*}{$\begin{array}{l}\text { Test } \\
\text { No. }\end{array}$} & \multirow{2}{*}{$\begin{array}{c}\mathrm{HR} \\
/{ }^{\circ} \mathrm{C} \cdot \min ^{-1}\end{array}$} & \multirow{2}{*}{$\begin{array}{l}\mathrm{T}_{\text {tor }} \\
/{ }^{\circ} \mathrm{C}\end{array}$} & \multicolumn{3}{|c|}{ Torrefaction performance parameters } & \multicolumn{2}{|c|}{ Calorific value/MJ $\cdot \mathrm{kg}^{-1}, \mathrm{db}$} \\
\hline & & & $M_{\mathrm{Y}} / \%$, daf & $I_{\mathrm{ED}}(-)$ & $E_{\mathrm{Y}} / \%$, daf & HHV & LHV \\
\hline 13 & 2.5 & 230 & $92.02 \pm 0.63$ & $1.07 \pm 0.02$ & $98.32 \pm 2.80$ & $20.91 \pm 0.68$ & $19.76 \pm 0.70$ \\
\hline 14 & 2.5 & 260 & $84.68 \pm 0.48$ & $1.12 \pm 0.04$ & $94.83 \pm 3.03$ & $21.66 \pm 0.59$ & $20.52 \pm 0.59$ \\
\hline 15 & 2.5 & 280 & $70.25 \pm 0.84$ & $1.20 \pm 0.04$ & $84.31 \pm 2.61$ & $23.26 \pm 0.80$ & $22.13 \pm 0.82$ \\
\hline 16 & 2.5 & 300 & $53.12 \pm 0.98$ & $1.38 \pm 0.05$ & $73.31 \pm 4.15$ & $26.31 \pm 0.87$ & $25.27 \pm 0.85$ \\
\hline 17 & 5 & 230 & $95.86 \pm 0.68$ & $1.04 \pm 0.01$ & $99.69 \pm 0.39$ & $20.05 \pm 0.53$ & $18.82 \pm 0.56$ \\
\hline 18 & 5 & 260 & $88.35 \pm 0.69$ & $1.09 \pm 0.02$ & $96.30 \pm 0.77$ & $20.86 \pm 1.18$ & $19.68 \pm 1.26$ \\
\hline 19 & 5 & 280 & $76.15 \pm 1.07$ & $1.14 \pm 0.04$ & $86.81 \pm 1.93$ & $22.57 \pm 1.52$ & $21.43 \pm 1.44$ \\
\hline 20 & 5 & 300 & $62.42 \pm 0.85$ & $1.28 \pm 0.06$ & $79.93 \pm 2.70$ & $24.87 \pm 1.52$ & $23.77 \pm 1.51$ \\
\hline 21 & 7.5 & 230 & $96.91 \pm 0.48$ & $1.03 \pm 0.02$ & $99.82 \pm 1.02$ & $19.99 \pm 0.65$ & $18.75 \pm 0.73$ \\
\hline 22 & 7.5 & 260 & $93.38 \pm 0.41$ & $1.06 \pm 0.03$ & $98.98 \pm 1.62$ & $20.53 \pm 0.99$ & $19.31 \pm 0.93$ \\
\hline 23 & 7.5 & 280 & $85.08 \pm 0.62$ & $1.12 \pm 0.02$ & $95.29 \pm 2.16$ & $21.97 \pm 1.64$ & $20.75 \pm 1.68$ \\
\hline 24 & 7.5 & 300 & $73.68 \pm 0.71$ & $1.18 \pm 0.05$ & $86.86 \pm 3.11$ & $23.46 \pm 1.14$ & $22.40 \pm 1.21$ \\
\hline
\end{tabular}

Note: daf means dry-ash-free; db means dry basis; HR means heating rate. 
Table 6 Main chemical properties of torrefied sorghum straw pellets

\begin{tabular}{|c|c|c|c|c|c|c|c|}
\hline \multirow{2}{*}{$\begin{array}{l}\text { Test } \\
\text { No. }\end{array}$} & \multicolumn{4}{|c|}{ Ultimate analysis/wt.\%, db } & \multicolumn{3}{|c|}{ Proximate analysis/wt. $\%, \mathrm{db}$} \\
\hline & $\mathrm{C}$ & $\mathrm{H}$ & $\mathrm{N}$ & $\mathrm{O}^{*}$ & Volatile & Ash & $\mathrm{FC}$ \\
\hline 13 & $51.40 \pm 0.41$ & $5.28 \pm 0.14$ & $0.31 \pm 0.02$ & $42.85 \pm 0.27$ & $82.61 \pm 0.66$ & $1.09 \pm 0.02$ & $15.29 \pm 0.64$ \\
\hline 14 & $54.76 \pm 0.43$ & $5.24 \pm 0.11$ & $0.23 \pm 0.04$ & $39.48 \pm 0.36$ & $79.78 \pm 0.80$ & $1.22 \pm 0.03$ & $17.99 \pm 0.77$ \\
\hline 15 & $60.85 \pm 0.95$ & $5.16 \pm 0.13$ & $0.31 \pm 0.02$ & $33.48 \pm 0.88$ & $70.37 \pm 1.23$ & $1.71 \pm 0.09$ & $26.90 \pm 1.13$ \\
\hline 16 & $66.02 \pm 1.01$ & $4.77 \pm 0.20$ & $0.30 \pm 0.03$ & $28.72 \pm 0.85$ & $62.38 \pm 1.95$ & $1.92 \pm 0.09$ & $34.68 \pm 1.86$ \\
\hline 17 & $50.51 \pm 0.54$ & $5.64 \pm 0.31$ & $0.23 \pm 0.01$ & $43.42 \pm 0.38$ & $84.52 \pm 0.70$ & $1.13 \pm 0.07$ & $13.34 \pm 0.66$ \\
\hline 18 & $53.25 \pm 0.78$ & $5.40 \pm 0.40$ & $0.32 \pm 0.04$ & $40.72 \pm 0.35$ & $81.27 \pm 0.56$ & $1.22 \pm 0.05$ & $16.50 \pm 0.52$ \\
\hline 19 & $56.81 \pm 1.20$ & $5.21 \pm 0.34$ & $0.32 \pm 0.04$ & $37.41 \pm 0.85$ & $75.68 \pm 1.03$ & $1.42 \pm 0.05$ & $21.88 \pm 1.00$ \\
\hline 20 & $61.65 \pm 1.68$ & $5.04 \pm 0.42$ & $0.42 \pm 0.03$ & $32.64 \pm 1.26$ & $65.16 \pm 1.86$ & $1.82 \pm 0.10$ & $32.00 \pm 1.76$ \\
\hline 21 & $49.07 \pm 0.45$ & $5.67 \pm 0.39$ & $0.36 \pm 0.05$ & $44.62 \pm 0.12$ & $85.74 \pm 0.91$ & $1.08 \pm 0.11$ & $12.17 \pm 0.81$ \\
\hline 22 & $51.23 \pm 0.82$ & $5.61 \pm 0.48$ & $0.28 \pm 0.03$ & $42.58 \pm 0.37$ & $84.39 \pm 0.66$ & $1.10 \pm 0.18$ & $13.50 \pm 0.56$ \\
\hline 24 & $56.43 \pm 1.46$ & $4.85 \pm 0.30$ & $0.36 \pm 0.04$ & $38.06 \pm 1.19$ & $73.91 \pm 1.48$ & $1.42 \pm 0.13$ & $23.66 \pm 1.35$ \\
\hline
\end{tabular}

Note: db means dry basis; * means by difference.

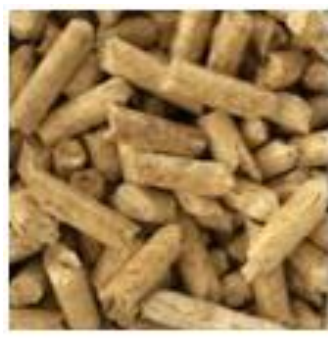

a. $30^{\circ} \mathrm{C}$

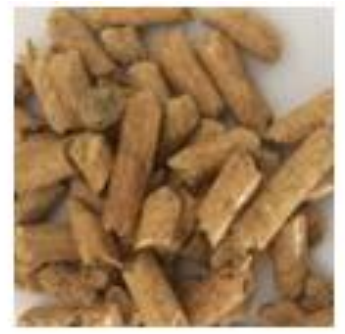

b. $230^{\circ} \mathrm{C}$

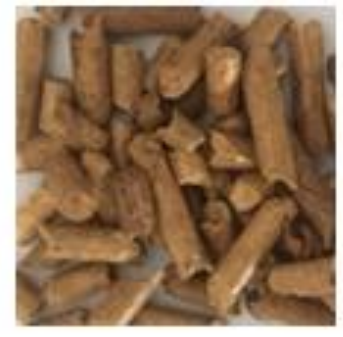

c. $260^{\circ} \mathrm{C}$

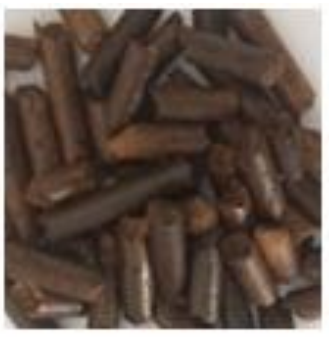

d. $280^{\circ} \mathrm{C}$

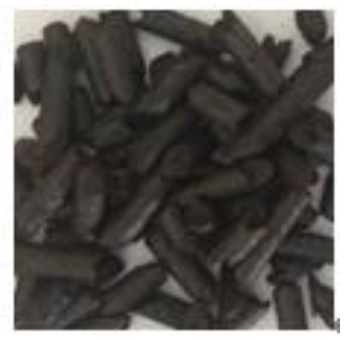

e. $300^{\circ} \mathrm{C}$

Figure 3 Snapshots of sorghum straw pellets torrefied at $7.5^{\circ} \mathrm{C} / \mathrm{min}$

Since the torrefaction is thermally driven, heat transfer is the first step and controlled the thermal degradation degree of the sorghum straw torrefaction. As shown in Figure 4, the sorghum straw torrefied in the fixed tube furnace can be divided into a boundary region (0.25-0.30 diameter of pellet) adjacent to the wall, in which the heat mainly transferred by conduction through wall-particle contacts and gases around the particles, and a bulk region far from the wall, in which the heat mainly transferred by conduction through particle-particle contacts (areas or points) and radiation through particle-particle and particle void to particle $\operatorname{void}^{[27]}$.
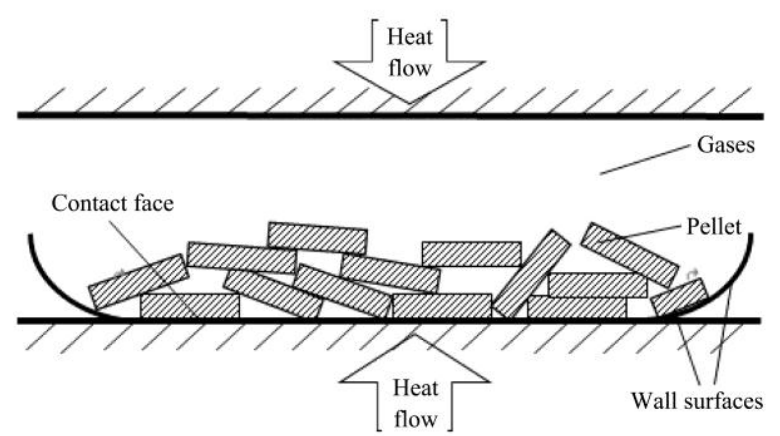

Figure 4 Schematic diagram of heat transfer during torrefaction

Due to the small particle size (less than $0.5 \mathrm{~mm}$ ), the sorghum straw powder can be regarded as uniform and isotropic from a macroscopic point. But for the pellets, the increased particle size increases voids between the pellets, making its overall structure similar to porous media. The increase in the void fraction of the pellets in the boundary region increases the heat transfer resistance and decreases the thermal conductivity, thereby lowers the heat transfer efficiency in the boundary layer. Hence, the yields and properties of the sorghum straw pellets were lower than those of the sorghum straw powder when the temperature was lower than $260^{\circ} \mathrm{C}$.

Compared with sorghum straw powder, the sorghum straw pellets in the bulk region have lower thermal diffusivity but higher thermal conductivity and volumetric specific heat, as listed in Table 2. Moreover, thermal decomposition will affect the heat transfer mechanism. Before thermal decomposition, the particle voids are mainly filled with nitrogen $\left(\mathrm{N}_{2}\right)$, which has a low conductivity, and neither emits nor absorbs radiation at low to moderate temperatures. Once decomposition begins, the gases in voids change from nitrogen to a mixture of $\mathrm{CO}_{2}$ and $\mathrm{CO}$, etc., which enhances the radiation from particle void to particle void. But the convection caused by the gases volatilized from the pellets delay the conductive wave into the pellets ${ }^{[28]}$. Thus, as the volatiles flow outwards, the effects of heat convection and radiation in heat transfer become more significant. In addition, the shrinkage of the pellets and the increase in the roughness of the pellet surface during torrefaction enhance the heat transfer efficiency outside the pellets.

The energy densification index of the sorghum straw pellets torrefied in the fixed bed was higher than that of the sorghum straw powder under the same operating conditions when the temperature was more than $260^{\circ} \mathrm{C}$, especially for the heating rate that more than $2.5^{\circ} \mathrm{C} / \mathrm{min}$. Moreover, the energy densification index of the sorghum straw pellets torrefaction decreased proportionally with the linearly increased heating rate, indicating that densification is an effective method to improve the thermal homogeneity of the fixed reactor for high heating rates and high temperatures.

\subsection{TG analysis}

The conversion degree $\alpha$ of the sample is calculated from the TG data by Equation (5): 


$$
\alpha=\frac{m_{0}-m_{\mathrm{T}}}{m_{0}-m_{\mathrm{f}}}
$$

where, $\alpha$ is the conversion degree; $m_{0}$ is the initial mass of the sample; $m_{\mathrm{T}}$ is the mass at temperature $T$, and $m_{\mathrm{f}}$ is the final mass of the sample.

The DTG curves of raw sorghum straw under different heating rates are compared in Figure 5. The main peak $\left(350^{\circ} \mathrm{C}-400^{\circ} \mathrm{C}\right)$ and the shoulder peak $\left(300^{\circ} \mathrm{C}-340^{\circ} \mathrm{C}\right)$ in the DTG curves correspond to the thermal decomposition of cellulose and hemicellulose, respectively ${ }^{[22]}$. About half of the sample mass loss occurred in a narrow temperature range $\left(200^{\circ} \mathrm{C}-375^{\circ} \mathrm{C}\right)$. The increase in heating rate resulted in a higher decomposition temperature, but the DTG profiles were similar.

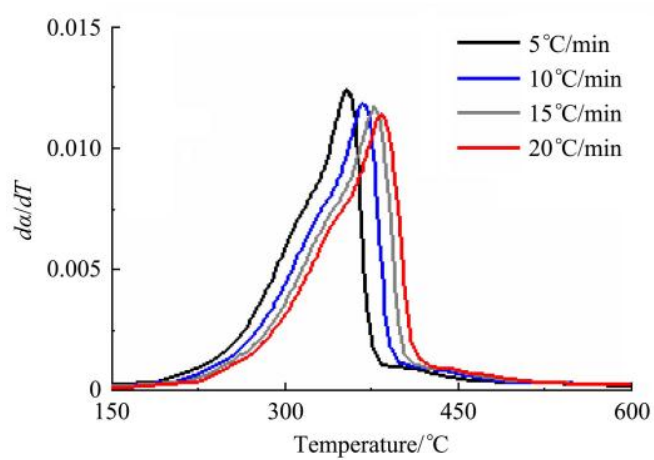

Figure 5 Comparison of DTG curves of raw sorghum straw under different heating rates

Figure 6 shows DTG curves of the solid products torrefied at different temperatures. The gradually disappeared shoulder peak in the DTG curves of the torrefied sorghum straw with the increased torrefaction temperature indicates the thermal decomposition of hemicellulose during the sorghum straw torrefaction $^{[25]}$. The sharp peak in the DTG curve of the sorghum straw torrefied at $300^{\circ} \mathrm{C}$ suggests that the considerable decomposition of hemicellulose and cellulose, resulting in the lower element ratios of oxygen to carbon $(\mathrm{O} / \mathrm{C})$ and hydrogen to carbon $(\mathrm{H} / \mathrm{C})$, as shown in Figure 2 . The above results were consistent with the study by Cao et al. ${ }^{[29]}$

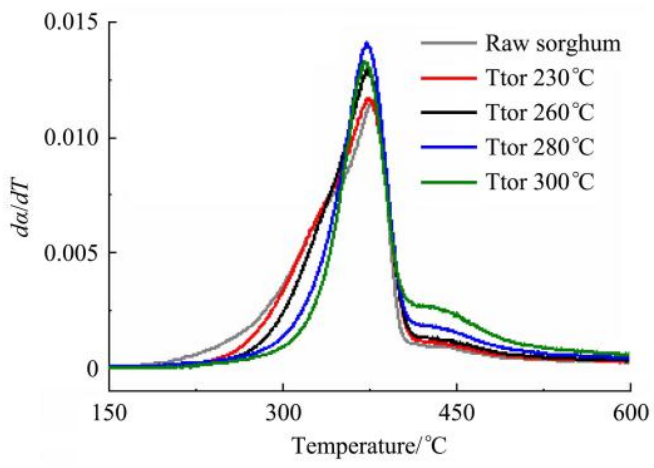

Figure 6 DTG curves of raw and torrefied sorghum straws at $15^{\circ} \mathrm{C} / \mathrm{min}$

The thermal decomposition rate of the biomass under nonisothermal conditions can be described by the Arrhenius equation:

$$
\frac{d \alpha}{d T}=\frac{A}{\beta} \exp \left(-\frac{E}{R T}\right) f(\alpha)
$$

where, $T$ is the absolute temperature; $\beta$ is the heating rate; $A$ is the pre-exponential factor; $E$ is the activation energy; $R$ is the ideal gas constant and $f(\alpha)$ is the differential conversion function that depends on the reaction mechanism.

According to the iso-conversional method, the activation energy $E$ is considered as a function of conversion degree $\alpha$. The conversion degree $\alpha$ is assumed to be a function of time $t$ and temperature $T$, then the integral conversion function $G(\alpha)$ is:

$$
\left.G(\alpha)=\int_{0}^{\alpha} \frac{d \alpha}{f(\alpha)}=\frac{A}{\beta} T-T_{0} \quad\right) \text { e }\left(\mathrm{x}-\mathrm{p} \frac{E}{R T}\right)
$$

where, $T_{0}$ is the initial temperature corresponding to $\alpha=0$.

For a given conversion degree, Equation (8) can be obtained from a series of nonisothermal curves, $i=1,2, \cdots, n$.

$$
\ln \left(\frac{\beta_{i}}{T_{\alpha, i}-T_{\alpha, i_{0}}}\right)=\ln \left(\frac{A_{\alpha}}{G(\alpha)}\right)-\frac{E_{\alpha}}{R T_{\alpha, i}}
$$

The plot $\ln \left(\beta_{\mathrm{i}} /\left(\mathrm{T}_{\alpha, i}-\mathrm{T}_{\alpha, i}\right)\right)$ versus $\left(\mathrm{T}_{\alpha, i}\right)^{-1}$ should be a straight line, activation energy $E_{\alpha}$ can be estimated from the slope of the straight line. The activation energy $E_{\alpha}$ of the raw sorghum straw and torrefied products with different temperatures are shown in Figure 7. The decomposition of the hemicellulose in the sorghum straw during torrefaction resulted in a decrease in the activation energy of the solid products. The higher the torrefaction temperature was, the lower the activation energy of the torrefied product was. The activation energy of the sorghum straw torrefied at $230^{\circ} \mathrm{C}$ changes little compared with the raw sorghum straw, which was mainly resulted from the moisture evaporation. The decreased activation energy of the sorghum straw treated at $260^{\circ} \mathrm{C}$ and $280^{\circ} \mathrm{C}$ mainly resulted from the decomposition of hemicellulose. The activation energy of the sorghum straw treated at $300^{\circ} \mathrm{C}$ decreased sharply indicates the decomposition of the cellulose.

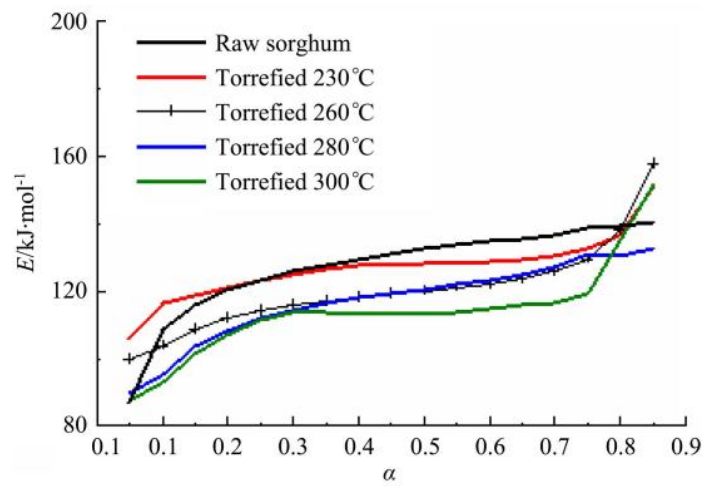

Figure 7 Comparison of the activation energy of raw and torrefied sorghum straw with different temperatures

\section{Conclusions}

The effects of operating conditions and pre-densification on the torrefaction of sorghum straw were investigated with a series of laboratory scale experiments based on a fixed tube furnace. The pyrolysis characteristics of the sorghum straw torrefied under various operating conditions were complemented by TGA tests. The higher heating value of the sorghum straw torrefied at a temperature above $280^{\circ} \mathrm{C}$ can be comparable to that of the low rank coal while maintains satisfactory mass and energy yields.

The high heating rate results in thermal heterogeneity throughout the sorghum straw torrefied in the fixed tube furnace. A low heating rate $\left(<5^{\circ} \mathrm{C} / \mathrm{min}\right)$ can promote heat transfer in the fixed tube during torrefaction. Densification has the potential to solve the heat transfer delaying and the material consolidation of the fixed tube, which can achieve uniform temperature distribution in the fixed tube furnace. However, the real-time effects of operating conditions and pre-densification on the internal 
temperature and pressure of the fixed tube furnace require further investigation. In addition, the effect of pre-densification on torrefaction in the rotary reactor needs further study.

\section{Acknowledgements}

This work was carried out in the Chinese Academy of Agricultural Engineering under the guidance of Dr. Zonglu Yao. The first authors thank the Chinese Academy of Agricultural Sciences and the Chinese Academy of Agricultural Engineering for their financial support.

\section{[References]}

[1] Zhang $\mathrm{L} \mathrm{H}, \mathrm{Xu} \mathrm{C} \mathrm{B}$, Champagne P. Overview of recent advances in thermo-chemical conversion of biomass. Energy Convers Manag, 2010; 51(5): 969-982.

[2] Wu X R, Mclaren J, Madl R, Wang D H. Biofuels from lignocellulosic biomass. In: Singh O, Harvey S (Ed.). Sustainable biotechnology, Dordrecht: Springer, 2010; pp.19-41.

[3] Awika J M, Rooney L W. Sorghum phytochemicals and their potential impact on human health. Phytochemistry, 2004; 65(9): 1199-1221.

[4] Karunanithy C, Wang Y, Muthukumarappan K, Pugalendhi S. Physiochemical characterization of briquettes made from different feedstocks. Biotechnol Res Int, 2012: 165202. doi: 10.1155/2012/165202.

[5] Wang Y P, Zhang S M, Wu Q H, Duan D L, Liu Y H, Ruan R, et al. Microwave-assisted pyrolysis of vegetable oil soapstock: Comparative study of rapeseed, sunflower, corn, soybean, rice, and peanut oil soapstock. Int J Agri \& Biol Eng, 2019; 12(6): 202-208.

[6] Li G, Ji F, Bai X, Zhou Y G, Dong R J, Huang Z G. Biorefinery process for production of bioactive compounds and bio-oil from Camellia oleifera shell. Int J Agri \& Biol Eng, 2019; 12(1): 208-213.

[7] Ersan Pütün. Catalytic pyrolysis of biomass: Effects of pyrolysis temperature, sweeping gas flow rate and $\mathrm{MgO}$ catalyst. Energy, 2010; 35(7): 2761-2766.

[8] Shang L, Nielsen N P K, Dahl J, Stelte W, Ahrenfeldt J, Holm J K, et al. Quality effects caused by torrefaction of pellets made from Scots pine. Fuel Process Technol, 2012; 101: 23-28.

[9] Isemin R L, Mikhalev A V, Muratova N S, KoghTatarenko V S, Pitsukha E A. Improving the efficiency of biowaste torrefaction. Thermal Engineering, 2019; 66(7): 521-526.

[10] Das O, Sarmah A K. Mechanism of waste biomass pyrolysis: Effect of physical and chemical pre-treatments. Sci Total Environ, 2015; 537: 323-334.

[11] Yu S H, Park J J, Kim M S, Kim H Y, Ryu C K, Lee Y W, et al. Improving energy density and grindability of wood pellets by dry torrefaction. Energy Fuels, 2019; 33(9): 8632-8639.

[12] Srinivasan V, Adhikari S, Chattanathan S A, Park S. Catalytic pyrolysis of torrefied biomass for hydrocarbons production. Energy Fuels, 2012;
26(12): 7347-7353.

[13] Wen J L, Sun S L, Yuan T Q, Xu F, Sun R C. Understanding the chemical and structural transformations of lignin macromolecule during torrefaction. Appl Energy, 2014; 121: 1-9.

[14] Peng F, Peng P, Xu F, Sun R C. Fractional purification and bioconversion of hemicelluloses. Biotechnol Adv, 2012; 30(4): 879-903.

[15] Chen Y Q, Liu B, Yang H P, Yang Q, Chen H P. Evolution of functional groups and pore structure during cotton and corn straws torrefaction and its correlation with hydrophobicity. Fuel, 2014; 137: 41-49.

[16] Jian J, Lu Z M, Yao S C, Li X, Song W F. Comparative study on pyrolysis of wet and dry torrefied beech wood and wheat straw. Energy Fuels, 2019; 33(4): 3267-3274.

[17] Yang H P, Yan R, Chen H P, Zheng C G. In-depth investigation of biomass pyrolysis based on three major components: Hemicellulose, cellulose and lignin. Energy Fuels, 2005; 20(1): 388-393.

[18] Shevchenko A L, Petrov A E, Sytchev G A, Zaichenko V M. Oxygen influence on the process of low-temperature pyrolysis of biomass. Journal of Physics Conference, 2019; 1147(1): 012091. doi: 10.1088/ 1742-6596/1147/1/012091.

[19] Van Soest P.J. Use of detergents in the analysis of fibrous feeds. II. A rapid method for the determination of fiber and lignin. Journal of the Association of Official Analytical Chemists, 1963; 49(4): 546-551.

[20] Brachi P, Miccio F, Miccio M, Ruoppolo G. Torrefaction of tomato peel residues in a fluidized bed of inert particles and a fixed-bed reactor. Energy \& Fuels, 2016; 30(6): 4858-4868.

[21] Grigiante M, Antolini D. Mass yield as guide parameter of the torrefaction process. An experimental study of the solid fuel properties referred to two types of biomass. Fuel, 2015; 153: 499-509.

[22] Yang H P, Yan R, Chen H P, Lee D H, Zheng C G. Characteristics of hemicellulose, cellulose and lignin pyrolysis. Fuel, 2007; 86(12-13): 1781-1788.

[23] Brachi P, Miccio F, Miccio M, Ruoppolo G. Torrefaction of tomato peel residues in a fluidized bed of inert particles and a fixed-bed reactor. Energy Fuels, 2016; 30(6): 4858-4868.

[24] Shen D K, Gu S, Bridgwater A V. The thermal performance of the polysaccharides extracted from hardwood: Cellulose and hemicellulose. Carbohydr Polym, 2010; 82(1): 39-45.

[25] Xu C, Donald J. Upgrading peat to gas and liquid fuels in supercritical water with catalysts. Fuel, 2012; 102: 16-25.

[26] Chew J J, Doshi V. Recent advances in biomass pretreatment Torrefaction fundamentals and technology. Renew Sust Energ Rev, 2011; 15(8): 4212-4222.

[27] Dixon A G. Fixed bed catalytic reactor modelling - the radial heat transfer problem. Can J Chem Eng, 2012; 90(3): 507-527.

[28] Pyle D L, Zaror C A. Heat transfer and kinetics in the low temperature pyrolysis of solids. Chem Eng Sci, 1984; 39(1): 147-158.

[29] Cao X F, Zhong L X, Peng X W, Sun S N, Li S M, Liu S J, et al Comparative study of the pyrolysis of lignocellulose and its major components: Characterization and overall distribution of their biochars and volatiles. Bioresour Technol, 2014; 155: 21-27. 